\title{
ARRANJOS PRODUTIVOS LOCAIS NO ESTADO DO PARÁ: LOCALIZAÇÃO ESPACIAL DAS ATIVIDADES FLORESTAL E DE MADEIRA E MOBILIÁRIO ${ }^{1}$
}

\author{
Gisalda Carvalho Filgueiras ${ }^{2}$ \\ Antônio Cordeiro de Santana ${ }^{3}$ \\ Alfredo Kingo Oyama Homma ${ }^{4}$ \\ Mário Miguel Amin Garcia Herreros ${ }^{5}$ \\ Paulo Luiz Contente de Barros ${ }^{6}$ \\ Fernando Antônio Teixeira Mendes ${ }^{7}$
}

Resumo: O Estado do Pará é o terceiro no ranking das exportações e concentra 75\% da madeira extraída de floresta nativa no país. Da madeira extraída na Amazônia Legal, 64\% destinam-se ao mercado nacional e $36 \%$, à exportação. O objetivo deste trabalho foi identificar e mapear, por meio do Índice de Concentração Normalizado (ICN), no período de 1998 a 2004, os municípios especializados nas atividades florestais e de madeira e mobiliário, com potencial para se transformar em Arranjos Produtivos Locais (APL). Os resultados indicaram nove municípios especializados, simultaneamente, nas duas atividades, o que sinaliza o desenho de políticas públicas destinadas a apoiar o desenvolvimento local sustentável a partir desses APL de base florestal.

Palavras-chave - Economia florestal, índices de concentração, desenvolvimento local.

Recebido em: 11/10/07 Aceito em: 28/04/08

2 Enga $^{\mathrm{a}}$ agr $^{\mathrm{a}}$ Doutoranda em Ciências Agrárias da UFRA. Técnica do Banco da Amazônia. E-mail: gisaldaf@yahoo.com.br.

3 Dr. Economia Rural. Professor da UFRA. E-mail: santana@naultilus.com.br.

4 Dr. Economia Rural. Pesquisador da EMBRAPA. E-mail: homma@oi.com.br.

5 PhD. Economia Agrícola, Professor Titular da UNAMA.

E-mail: maramin@amazon.com.br.

6 Dr Eng ${ }^{\circ}$ Florestal, Professor da UFRA. E-mail: char@amazon.com.br.

7 Eng $^{\circ}$ agr $^{\circ}$. Dr. Economia Agrícola. Professor da UNAMA.

E-mail: fernando@ufpa.br. 


\section{Introdução}

A exploração de recursos naturais é uma atividade que causa grande impacto no meio ambiente. A extração de recursos florestais, produtos madeireiros ou não, tem causado grandes perdas ambientais na Amazônia. Nesse sentido, o grau de intensidade de uso dos recursos da floresta tropical depende, essencialmente, do nível organizacional e tecnológico que cada sociedade detém. No Estado do Pará, nos últimos 40 anos do século passado, o crescimento econômico vem se processando pelo intenso uso do solo, o que tem gerado preocupação, na sociedade como um todo, com o fato de o desflorestamento vir aumentando de forma substancial.

Sabe-se, entretanto, que o aumento no uso de recursos naturais no Pará se deu como resultado de políticas públicas e privadas que visavam inserir esta economia no resto do país e do mundo, o que foi feito por meio de investimentos em infra-estrutura e incentivos fiscais, de modo a tornar um centro de atração para os investidores. De fato, isto não ocorreu e, ao contrário, as empresas que se instalaram no Pará obtiveram grandes incentivos, sejam fiscais e, ou, creditícios, de forma que ocorreu intenso de fluxo migratório, cujo resultado foi a expansão da fronteira agrícola e, conseqüentemente, forte impacto na floresta amazônica, por meio do desmatamento de grandes áreas, cuja taxa foi de 3\% ao ano, no período de 1989 a 2005, conforme dados do Instituto Nacional de Pesquisa Espacial (INPE, 2006).

Por isso, diversos estudos confirmaram que a expansão da agropecuária na Amazônia e no Pará tem ocorrido com a abertura de novas áreas ao invés do aumento da produtividade das culturas exploradas, nas décadas dos anos de 70 a 90, conforme Filgueiras (2002), Homma (1981) e Santana (1988). Exceções são as culturas industriais (dendê, café, soja, pimentado-reino, etc.), cujo crescimento tem se dado por meio de inovações tecnológicas, em razão da demanda do mercado nacional e internacional. Logo, no Pará, o maior produtor de madeiras em tora no país, predomina também o modus operandi (tradicional), sem que haja o emprego de tecnologias para extração de madeira para diversos fins. Assim, a utilização 
de recursos naturais neste Estado, com destaque aos produtos da floresta, principalmente a madeira, o carvão vegetal e a lenha, vem se processando em demasia desde os anos de 1970, para atender, inclusive, à demanda internacional de madeira, bem como ao próprio mercado interno, seja local, regional e nacional.

Sabe-se, também, que as atividades florestal e de madeira e mobiliário são complementares, logo, o propósito de investigação deste estudo é determinar em quais localidades essas atividades vêm ao longo dos anos contribuindo para o crescimento econômico estadual na geração de empregos, rendas e divisas, devido à especialização de sua produção em alguns municípios paraenses.

Desse modo, os Arranjos Produtivos Locais (APL) surgem como instrumentos de fortalecimento da produção local, envolvendo toda a dinâmica para alcançar a sustentabilidade de determinada territorialidade (locus), que, por definição, são sistemas de produção enraizados ao local graças às vantagens competitivas que aquela própria localização proporciona, ou seja, as vantagens competitivas locacionais, em geral, estão associadas à ação cooperada e à maior facilidade de aperfeiçoamento do conhecimento técnico e comercial. Graças a elas, pequenas e médias empresas enraizadas em seu local de origem se tornariam mais capacitadas a competir com grandes empresas globais (Santos; Diniz; Barbosa, 2005). Portanto, o desenvolvimento em regiões que atualmente se encontram nesse processo, como o Pará, é possível por meio de APL, tendo como definição apropriada a este trabalho a de Lastres e Cassiolato ${ }^{8}$, por meio da RedeSist, para qual esses arranjos se constituem em sistemas, de tal modo que:

\footnotetext{
Coordenadores: Lastres, H.M.M.; Cassiolato, J.E. 2005. Mobilizando conhecimento para desenvolver arranjos e sistemas produtivos e inovativos locais de micro e pequeno empresas no Brasil. Disponível em: htpp// redesist.ie.ufrj.br/glossário.php. Acesso: mar.2006.
} 
Sistemas Produtivos e Inovativos Locais (SPIL) são conjuntos de atores econômicos, políticos e sociais, localizados em um mesmo território, desenvolvendo atividades econômicas correlatas $e$ que apresentam vínculos expressivos de produção, interação, cooperação $e$ aprendizagem. Os SPIL geralmente incluem empresas - produtoras de bens e serviços finais, fornecedoras de equipamentos e outros insumos, prestadoras de serviços, comercializadoras, clientes, etc., cooperativas, associações e representações - e demais organizações voltadas à formação e treinamento de recursos humanos, informação, pesquisa, desenvolvimento $e$ engenharia, promoção e financiamento. (Lastres; Cassiolato, 2005; p.1).

Nesse contexto, este estudo propôs identificar os APL das atividades florestal e de madeira e mobiliário no Estado do Pará. Para isso, utilizaramse métodos de identificação para evidenciar os municípios que possuem potenciais para induzir o desenvolvimento local, haja vista que a produção e o emprego concentrados espacialmente são importantes para organizar o ambiente das empresas e a ação de seus agentes e, com isso, produzir economias externas, que, segundo Marshall (1982), surgem a partir do processo geral do desenvolvimento de aglomerações industriais. Esse fato é explicado porque a localidade funciona como um elemento que congrega todas as ações interativas entre pessoas ${ }^{9}$ e empresas, na busca de melhores alternativas para produzir determinado bem, inovar em tecnologias, vender, trocar experiências, com vistas em aumentar suas vantagens comparativas com relação aos demais concorrentes. Por isso, a problemática da exploração da floresta tropical no Pará precisa priorizar investimentos na formação de capital social, capital humano, capital

9 Marshall (1982) considerou o conhecimento tácito como elemento importante para desenvolver os aglomerados produtivos, atualmente denominado de clusters de empresas. 
Gisalda Carvalho Filgueiras, Antônio Cordeiro de Santana, Alfredo Kingo Oyama Homma, Mário

Miguel Amin Garcia Herreros, Paulo Luiz Contente de Barros \& Fernando Antônio Teixeira Mendes

financeiro e tecnológico nas localidades que existam reais condições de produção e, ou, vantagens comparativas, aqui denotada como especializações na utilização de mão-de-obra formal.

\section{Abordagem teórica sobre desenvolvimento local}

O fortalecimento das atividades locais parte do princípio de que as especializações locais se explicam pelas conexões que determinadas atividades de um ou mais setores desenvolvem tanto para trás quanto para frente, ou seja, relações inter e intra-setoriais. A ocorrência de tais conexões indica a existência de empresas que operam com retornos crescentes, que é o motor principal do desenvolvimento de APL e, conseqüentemente, do desenvolvimento local, pois engloba ainda o conhecimento dos agentes locais, segundo ressaltado por Marshall (982), Santana, A. C.; Santana, A. L; Filgueiras (2005). Adicionalmente, pequenas empresas que operam com retornos de escala implicam menores custos de transações espaciais, que, na visão de Fujita, Krugman e Venables (2002), seriam os custos de fretes, simplesmente.

De outro modo, as questões relativas a aglomerações e, ou, dispersões de atividades produtivas assumem papel preponderante na atual conjuntura, para se pensar em desenvolver uma "região". Dessa forma, (re) surge a localidade enquanto espaço e território, para se processar o desenvolvimento de idéias sobre a importância de atividades correlacionadas ocuparem o mesmo espaço geográfico e justificarem a causa das disparidades regionais (Haddad et al., 1989). Embora não seja uma idéia nova, a produção especializada de determinado produto em dado território implica a geração de emprego, renda e organização social, que opera para formação de arranjos produtivos e obtenção de ganhos competitivos, de modo a fortalecer a própria atividade no local onde ela se efetiva.

Assim, as vantagens das aglomerações produtivas têm, desde cedo, despertado os teóricos para a importância da localidade (locus) onde 
ocorre a produção em si. É assim que a Teoria da Localização se estrutura ou surge, essencialmente, na interpretação das decisões empresariais, em uma economia de mercado, sobre o melhor sítio onde se localizar (Ferreira, 1989).

Um dos primeiros teóricos a pensar a localidade como um fator de desenvolvimento regional foi Von Thünen (1826) (apud Rolim, 1999), cujo modelo preconizava que usos mais intensos do solo (exploração agrícola) se alocariam próximos ao centro (cidade), já que os preços de aluguéis das terras seriam decrescentes quanto mais próximos da periferia (ao redor da cidade). Na contribuição desse autor, a melhoria do sistema de transportes e a necessidade da mobilidade da mão-de-obra e de outros insumos tenderiam a reduzir a importância da distância e da perecibilidade dos produtos, principalmente agrícolas.

A teoria de localização, de Alfred Weber (apud Rolim, 1999), parte dos custos de transação relativos ao transporte em uma área industrial, assim como do deslocamento de mão-de-obra, denominado de forças aglomerativas. Essa teoria foi desenvolvida em 1909, por Weber, e prescreve que a localização final de uma indústria será o ponto em que os custos de transportes da matéria-prima até a localização da empresa e entrega dos produtos finais no mercado sejam mínimos.

Sintetizando todas essas teorias, tem-se o modelo Isard, de 1956 (apud Rolim, 1999), que destaca o ponto comum relativo aos custos de transações (transportes) para a localização ótima da empresa, contrabalanceada com os custos da mão-de-obra, o que determina o fator conhecido como economia de aglomeração. Todavia, é com o conceito de distrito industrial, de Alfred Marshall (1890), que a conglomeração produtiva se torna importante, como condicionante, para desenvolver economicamente uma região. Nesse conceito, Marshall (1982) demonstra que a produção, em larga escala, das grandes empresas pode ser obtida por pequenas e médias empresas que se encontram concentradas em dado espaço geográfico. É na localidade de um território 
Gisalda Carvalho Filgueiras, Antônio Cordeiro de Santana, Alfredo Kingo Oyama Homma, Mário Miguel Amin Garcia Herreros, Paulo Luiz Contente de Barros \& Fernando Antônio Teixeira Mendes

que a organização produtiva se realiza, em conjunto, com fortes características socioculturais.

Santana (2004) confirmou a idéia de que aglomerados econômicos e, ou, APL têm raízes no trabalho dos economistas clássicos (Ricardo, Von Thünen e Weber), assim como nas idéias de Marshall (1982), atualizadas por Fujita, Krugman e Venables (2002), que destacam a importância da aglomeração de pequenas empresas que operam com retornos de escala, que acabaram por ganhar relevância sobre as idéias/teorias que envolviam a nova geografia econômica, ciência regional e economia urbana.

Por fim, o conceito operacional de APL, conforme proposto por Cassiolato e Lastres (2003, p. 31), estipula que, "onde houver produção de qualquer bem e,ou, serviço, haverá sempre um arranjo em seu entorno, envolvendo atividades e atores relacionados à sua comercialização, assim como o fornecimento de matérias-primas, máquinas e demais insumos".

Como se percebe, a nova perspectiva de desenvolvimento local perpassa pela idéia de aglomerados produtivos e, ou, APL, que ganham nova dimensão enquanto um processo dinâmico para desenvolver local ou endogenamente um território e aí promover os ganhos econômicos, que possam ter maior usufruto para a economia local, e o desenvolvimento dos agentes locais inseridos na construção desse novo modelo de desenvolvimento, por isso, a necessidade de determinar os APL de base florestal no Estado do Pará.

\section{Procedimentos metodológicos}

Nesta seção cita-se, de modo resumido, a metodologia de identificação de APL para o Pará, por constituir a área da pesquisa, conforme anteriormente justificado, devido ao peso da economia na atividade de base florestal e demonstrada pelos dados da Associação das Indústrias Exportadoras de Madeira do Estado do Pará (AIMEX, 2006), que fornecem maior subsídio de como a atividade madeira e mobiliário, atualmente, encontra-se estruturada. 


\subsection{Base de dados}

O Estado do Pará destaca-se com considerável presença na base de exploração florestal, com forte participação das variáveis relacionadas com os estados da Amazônia. Em relação aos pólos produtores, o Pará participou com 40,24\%; o número de empresas chegou a 50,83\%; a renda bruta anual gerada foi de 52,22\%; e a exportação representou $61,01 \%$ em 2004. No mesmo ano, o consumo atingiu 45,51\% do total produzido na região (AIMEX, 2006).

Assim, partiu-se de dados secundários, utilizando como variável o emprego formal para identificar os municípios especializados em APL florestal e de madeira e mobiliário, nos 143 municípios paraenses. A base de informações foi da Relação Anual de Informações Sociais (RAIS), emitida pelo Ministério do Trabalho e Emprego (MTE), por meio da qual se construíram os índices de concentração (BRASIL, 1998 - 2004).

\subsection{Modelo de análise}

A localização espacial da produção, segundo seu potencial de desenvolvimento, é dada pelos seguintes indicadores, de acordo com Crocco et al. (2003) e Santana (2004, 2005):

a) Índice de Especialização ou Quociente Locacional (QL): serve para determinar se um município, em particular, possui especialização em dada atividade e é calculado com base na razão entre duas estruturas econômicas.

$$
Q L=\left(\frac{E_{i j} / E_{j}}{E_{i P} / E_{P}}\right)
$$


em que $E_{i j}$ é o emprego da atividade $\mathbf{i}$ no município em estudo $\mathbf{j} ; E_{j}$, emprego de todas as atividades que constam no município $\mathbf{j} ; E_{i P}$, emprego da atividade i no Pará; $E_{P}$, emprego de todas as atividades no Pará. O município será considerado especializado se apresentar QL > 1 .

\section{b) Índice de Concentração de Hirschman-Herfindahl (IHH)} Modificado: utilizado para captar o real peso da atividade na estrutura produtiva local. É definido da seguinte forma:

$$
I H H=\left[\left(\frac{E_{i j}}{E_{i P}}\right)-\left(\frac{E_{j}}{E_{P}}\right)\right] .
$$

O IHH modificado permite comparar o peso da atividade i do município j, na atividade i do Pará, com o peso da estrutura produtiva do município $\mathbf{j}$, na estrutura do Estado como um todo. Um valor positivo indica que a atividade $\mathbf{i}$ do município $\mathbf{j}$, no estado, está mais concentrada e, portanto, com maior poder de atração econômica, dada sua especialização em tal atividade. O município será considerado especializado se apresentar IHH $>0$.

c) Índice de Participação Relativa (PR): terceiro indicador que foi utilizado para captar a importância da atividade $\mathbf{i}$, do município j, diante do total de emprego na referida atividade para o Estado do Pará. A fórmula é dada por:

$$
P R=\left(\frac{E_{i j}}{E_{i P}}\right) .
$$

Este indicador varia entre zero e um. Quanto mais próximo for de um, maior será a importância da atividade i no município j, no Pará. O município será considerado especializado se apresentar PR > 1\% 
d) Índice de Concentração Normalizado (ICN): os três indicadores descritos fornecem os insumos básicos para a construção de um indicador mais geral e consistente de concentração empresarial ligado a uma atividade econômica em um município, denominado de índice de concentração normalizado (ICN), dado pela seguinte fórmula:

$$
I C N_{i j}=\theta_{1} Q L_{i j}+\theta_{2} I H H_{i j}+\theta_{3} P R_{i j}
$$

em que $\theta$ são os pesos de cada um dos indicadores para cada atividade produtiva em análise. No cálculo dos pesos $\theta$, de cada um dos índices especificados na equação 4, empregou-se o método da análise de componentes principais. O município será considerado especializado se apresentar ICN > ICM médio.

e) Modelo de Componentes Principais: o modelo de componentes principais, com $\mathbf{m}$ componentes e $\mathbf{p}$ variáveis $(\mathbf{q}<\mathbf{p})$, pode ser escrito como na equação 5 .

$$
\begin{gathered}
C P_{1}=\gamma_{11} \\
C P_{2}=\gamma_{21} \\
\quad \text { м } \\
C P_{q}=\gamma_{m 1}
\end{gathered}
$$

em que $C P_{i}$ são as i-ésimas componentes principais $(i=1,2, \ldots, \mathrm{q}) ; g_{i j}$ coeficientes relacionados com cada variável; $X_{j}, \mathrm{j}$-ésimas variáveis $(\mathrm{j}=$ $1,2, \ldots, p)$. 
Gisalda Carvalho Filgueiras, Antônio Cordeiro de Santana, Alfredo Kingo Oyama Homma, Mário Miguel Amin Garcia Herreros, Paulo Luiz Contente de Barros \& Fernando Antônio Teixeira Mendes

A descrição da técnica de componentes principais está em Crocco et al. (2003) e Santana (2004).

\section{Resultados e discussões}

A variável emprego formal, neste trabalho, foi utilizada para calcular os índices de concentração normalizados (ICN).

\subsection{Resultados dos índices de concentração}

Os empregos formais são aqueles pelos quais as empresas registram a carteira de seus empregados, logo, beneficiam tantos os trabalhadores e, ou, profissionais, quanto fortalecem a economia estadual, uma vez que recolhem tributos ao governo. Os benefícios para os empregados são muitos, como garantia por tempo de serviço, que se traduz em aposentadoria, assistência médica, melhores oportunidades de capacitação/treinamento na mão-de-obra, enfïm, evolução em ascensão social. Em outras palavras, a variável emprego está diretamente relacionada com capital social e humano e com a dinâmica na relação das empresas com seus empregados, com fornecedores e clientes, portanto, com o desenvolvimento local e, ou, endógeno, que se fortalece a partir de tais relações socioeconômicas.

\subsubsection{Localização espacial dos municípios especializados nas atividades florestal e de madeira e mobiliário por meio do Índice de Concentração Normalizado (ICN)}

Os resultados dos ICN constam na Tabela 1. Consideraram-se como municípios especializados nas atividades florestal e de madeira e mobiliário aqueles que apresentaram um índice de valor igual ou superior ao ICN médio do Estado, a cada ano (Tabela 1). 
Em linhas gerais, os resultados do ICN mostraram que houve expansão das atividades econômicas no Estado do Pará, denotada pelo número de APL existentes em 1998, quando comparado com o de 2004. O número de APL, para as duas atividades de base florestal, evoluiu de 47, em 1998, para 52 APL, em 2004, uma variação positiva de 10,64\%.

Tabela 1 - Índice de Concentração Normalizado (ICN) Médio Estadual das atividades florestal e de madeira e mobiliário no Pará, 1998 a 2004

\begin{tabular}{lcc}
\hline Ano & ICN florestal & ICN madeira e mobiliário \\
\hline 1998 & 0,5630 & 0,6369 \\
1999 & 0,5438 & 0,5806 \\
2000 & 0,7112 & 0,5086 \\
2001 & 0,4428 & 0,4793 \\
2002 & 0,6030 & 0,4964 \\
2003 & 0,4016 & 0,4755 \\
2004 & 0,4655 & 0,4824 \\
\hline
\end{tabular}

Fonte: dados da pesquisa.

Ao destacar somente os ICN com valores médios das atividades florestal e de madeira e mobiliário, objeto deste estudo, verifica-se que a menor expansão (em termos absolutos) ocorreu na atividade florestal (de 15, em 1998, saltou para 17, em 2004) e madeira e mobiliário, que, no mesmo período, cresceu de 32 para 35. Logo, percebeu-se maior restrição na expansão da atividade florestal. Considerando a presença simultânea das duas atividades no mesmo município, constatou-se, no ano de 1998, que apenas seis apresentaram especialidade nas duas atividades e, em 
Gisalda Carvalho Filgueiras, Antônio Cordeiro de Santana, Alfredo Kingo Oyama Homma, Mário Miguel Amin Garcia Herreros, Paulo Luiz Contente de Barros \& Fernando Antônio Teixeira Mendes

2004, tais aglomerações se encontraram em nove municípios. No entanto, os resultados do ICN, da Tabela 1, apresentam oscilações e queda a partir de 2000, para o APL florestal, e queda linear ao longo do período, para o APL de madeira e mobiliário. Isso resulta no encolhimento da atividade formal das serrarias, pois muitas delas fecharam e, ou, passaram a operar de forma ilegal, em razão do aumento da fiscalização e das exigências de planos de manejo por parte do Instituto Brasileiro do Meio Ambiente e dos Recursos Naturais e Renováveis (IBAMA) e da Secretaria do Meio Ambiente (SEMA). Mesmo as empresas formais não informaram o número total de empregos. Além disso, as empresas de porte médio e grande introduziram máquinas fortemente substituidoras de mão-de-obra, principalmente nas empresas de laminados e compensados. Essa perda de participação dos empregos formais da cadeia produtiva da madeira, em relação ao comércio e serviços nos municípios analisados, contribuiu para redução do valor do ICN.

Na Tabela 2 visualizam-se a evolução das duas atividades, comparativamente, por meio do ICN médio estadual e os municípios onde as especializações se concentravam. Em 2002, foram 13 o número de municípios que apresentaram as concentrações nas duas atividades (APL florestal e de madeira e mobiliário). 
Gisalda Carvalho Filgueiras, Antônio Cordeiro de Santana, Alfredo Kingo Oyama Homma, Mário Miguel Amin Garcia Herreros, Paulo Luiz Contente de Barros \& Fernando Antônio Teixeira Mendes

Com relação à variação no número de municípios especializados nos referidos APL ao longo do período, tem-se que muitas empresas são abertas em áreas das novas fronteiras para o aproveitamento das madeiras oriundas das áreas desmatadas para pecuária e, ou, lavouras.

Destaca-se que algumas empresas extrativas (florestais) migram para novos municípios em busca de madeiras nobres que ficam mais próximas; assim, essas novas localidades passam a serem intensivamente exploradas. Muitas vezes, as empresas novas e as que migram para as áreas mais distantes dos pólos madeireiros tradicionais realizam apenas a etapa de serrar madeira, para viabilizar o custo de transporte em longas distâncias (Santana, 2002). Esse processo de mudança justifica, parcialmente, o avanço da fronteira agrícola e, conseqüentemente, o aumento do desmatamento no Estado do Pará.

Além disso, existem outros fatores que impedem a produção de madeira em tora, como a fiscalização por parte dos órgãos que controlam o cumprimento da atual legislação ambiental. Às vezes, ocorrem quedas significativas na atuação (produção) dessas empresas, o que faz com que a economia local sofra redução na renda, como aconteceu recentemente no município de Tailândia. De outro modo, as empresas da atividade extrativa florestal, em linhas gerais, são consideradas rotativas, pois elas se implantam de forma precária em alguma localidade e, ou, região onde existem matérias-primas para extrair madeira (nobre, primeiramente). No início, a exploração é intensa num curto espaço de tempo. Na mesma época, já se instalam algumas serrarias e, depois, as empresas de madeira e mobiliário. O ciclo de vida dessas empresas depende do avanço tecnológico utilizado, da especialização da mão-deobra naquela localidade e de a madeira ser mais ou menos abundante. Por isso, a sobrevivência dessas empresas decorre do grau de organização com que elas operam. Todavia, sabe-se que as empresas de madeira e mobiliário têm menor mobilidade, em razão da especificidade e do alto custo dos ativos. 
Além disso, a explicação do decréscimo no número de municípios especializados nas atividades florestal e de madeira e mobiliário deve-se à maior fiscalização por parte do IBAMA, que começou justamente em 2002 e atingiu seu apogeu em 2004. Em 2005 e 2006, foram realizadas diversas operações para coibir o transporte e venda de madeiras em tora extraídas ilegalmente da floresta tropical, o que pode resultar, por algum tempo, na suspensão das transações desse produto não formalizadas dentro da lei.

Observa-se, na Tabela 2, que o município de Dom Eliseu teve maior freqüência em ambas as especializações, já que, no período de sete anos (1998 a 2004), esteve em seis. Os municípios que se destacaram, em cinco anos dos sete pesquisados, foram Moju, Itupiranga e Ulianópolis.

Esses resultados eram esperados, uma vez que, no Pará, as indústrias de base florestal, no que concerne à organização e à exploração de recursos naturais, principalmente do produto madeira, permanecem pouco desenvolvidas e processam, ainda, de modo informal.

As explorações se dão numa localidade de abundância relativa de matériaprima, e os extratores vendem para as madeireiras; aí, uma base organizativa de madeireiros para refazer o replantio (investir), enfim, utilizar manejos que demandem mais mão-de-obra contratada e fornecimento contínuo da matéria-prima para ser elaborado e, ou, beneficiado, está em processo de formação. Pelos resultados da Tabela 2, chega-se à conclusão que em apenas nove municípios, dos 143 existentes e pesquisados em 2004, ocorreram evidências de municípios especializados, simultaneamente, nas duas atividades de exploração florestal. Observa-se, na Tabela 2, que os mesmos municípios especializados em 2003 foram os mesmos de 2004 (Abel Figueiredo, Dom Eliseu, Itupiranga, Moju, Novo Progresso, Paragominas, Porto de Moz, Rondon do Pará e Ulianópolis). Desses nove, apenas três não fazem parte do Sudeste Paraense (Moju, Porto de Moz e Novo Progresso). 
Gisalda Carvalho Filgueiras, Antônio Cordeiro de Santana, Alfredo Kingo Oyama Homma, Mário Miguel Amin Garcia Herreros, Paulo Luiz Contente de Barros \& Fernando Antônio Teixeira Mendes

O município de Paragominas, na microrregião do mesmo nome, é um dos mais desenvolvidos em reflorestamento, manejo e processos na elaboração de móveis. Destaca-se que algumas Organizações NãoGovernamentais (ONG), sindicatos de madeireiros, empresários e o próprio governo tentam estimular e, ou, fazer reflorestamento de determinadas espécies. Recentemente, foi noticiado na imprensa local que a Companhia Vale do Rio Doce (CVRD) estaria incentivando o processo de reflorestamento de mudas de Eucalyptus.

Ressalta-se que, com o avanço da escassez dos recursos florestais (madeira) e com a pressão ambiental, atualmente as empresas e a própria atividade migram para outras áreas de novas fronteiras agrícolas, como o município de Novo Progresso (Sudoeste Paraense). Em termos de madeira certificada no Pará, este produto encontra-se praticamente em processo inicial, pois dados de 2004 registravam que apenas nove empresas operavam com a certificação do selo emitido pelo Forest Stewardship Council (FSC), com manejo de florestas nativas no Estado do Pará, o que correspondia a uma área manejada de 1.367.360 hectares de mata (Filgueiras, 2007).

Em comparação com outros municípios, Dom Eliseu apenas registrou maior número de empregos formais com relação aos demais, nas duas atividades, o que indica maior organização na exploração dos recursos florestais.

Na Tabela 3 visualizam-se as variáveis socioeconômicas dos nove municípios especializados nas atividades de base florestal. Percebe-se uma renda per capita maior quanto à média do Estado ( $\mathrm{R} \$ 4.992,00)$, com relação aos municípios com maior especialização nas duas atividades: Abel Figueiredo, Dom Eliseu, Paragominas e Ulianopolis. 
Tabela 3 - Dados socioeconômicos dos municípios especializados em produtos nas atividades de base florestal no Estado do Pará

Fonte: SECEX/MDIC.

(*) Previsão para 2005 feito pelo IBGE e SEPOF-PA

Legenda: IDHm - Índice de Desenvolvimento Humano municipal

FOB: Free On Board

No Mapa 1, visualizam-se as interligações dos municípios do Sudeste Paraense, que formam uma área de exploração de madeira contínua (Abel Figueiredo, Rondon do Pará, Dom Eliseu, Ulianópolis e Paragominas). Em relação à distância espacial, Novo Progresso (Sudoeste), Porto de Moz (Marajó) e Moju (Nordeste Paraense) ficam longe de uma produção concentrada de produtos madeireiros ou nãomadeireiros do Sudeste Paraense.

Município

\section{Abel}

Figueiredo

Dom Eliseu

Itupiranga

Moju

Novo Progresso

Paragominas

Porto de Moz

Rondon do Par

Ulianópolis

Total 
Gisalda Carvalho Filgueiras, Antônio Cordeiro de Santana, Alfredo Kingo Oyama Homma, Mário Miguel Amin Garcia Herreros, Paulo Luiz Contente de Barros \& Fernando Antônio Teixeira Mendes

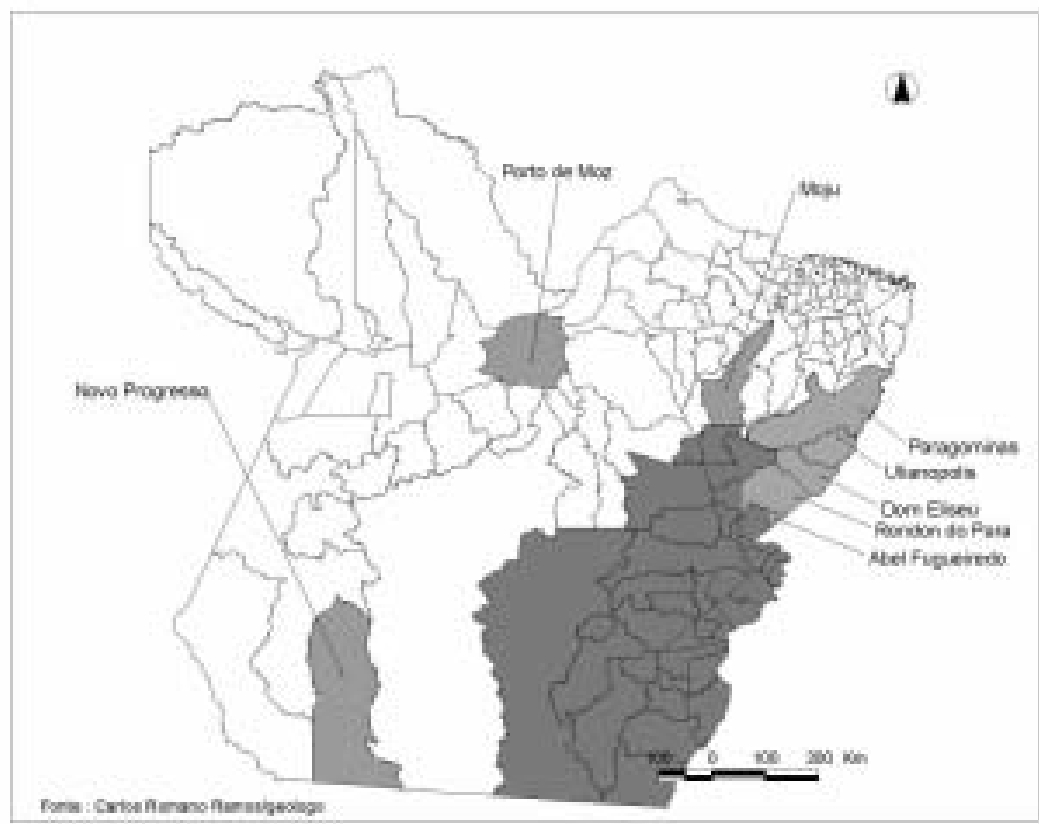

vidade

2003 e

stiam,

leira e

mente.

ativas,

na vez

iiderar

nciais

modo 
simultâneo, em 2003 e 2004 foram nove (Abel Figueiredo, Dom Eliseu, Itupiranga, Moju, Novo Progresso, Paragominas, Porto de Moz, Rondon do Pará e Ulianópolis). Com este resultado, ações de políticas públicas e privadas seriam indicadas para melhor estruturar e fortalecer, localmente, essas duas atividades produtivas e, ou, APL, haja vista o interrelacionamento forte entre as duas, uma vez que uma depende dos insumos da outra, além de que devam ser estimuladas conjuntamente, para haver equilíbrio no fortalecimento destas, além de considerar as demais atividades (serviço, transporte, comércio e instituições financeiras) que a complementam, de modo que resultem em um desenvolvimento regional com base sustentável, levando em consideração as relações a montante e a jusante que estas proporcionam, fortalecendo a territorialidade como um fator decisivo para impulsionar a economia estadual, nos moldes de Pólos de Desenvolvimento Regional.

\section{Referências}

ASSOCIAÇÃO DAS INDÚSTRIAS EXPORTADORAS DE MADEIRA NO ESTADO DO PARÁ. Estatística e exportação. Belém, 2004. Disponível: www.aimex.com.br. Acesso em: mar.2006.

BRASIL. Ministério do Trabalho e do Emprego. Relação Anual de Informações Sociais (RAIS). Brasília, DF, 1998 - 2004.

CASSIOLATO, J. E.; LASTRES, H. M. M. O foco em arranjos produtivos e inovativos locais de micro e pequenas empresas. In: LASTRES, H. M. M.; CASSIOLATO, J. E.; MACIEL, M. L. Pequena empresa: cooperação e desevolvimento local. Rio de Janeiro: Relume Dumará: UFRJ, Instituto de Economia, 2003. p. 21-34.

CROCCO, M.A.; GALINARI, R.; SANTOS, F.; LEMOS, M.B.; SIMÕES, R. Metodologia de identificação de arranjos produtivos locais potenciais: uma nota técnica. Belo Horizonte: CEDEPLAR, FACE, UFMG, 2003. (Texto para discussão nº 191). Abril de 2003. 
Gisalda Carvalho Filgueiras, Antônio Cordeiro de Santana, Alfredo Kingo Oyama Homma, Mário Miguel Amin Garcia Herreros, Paulo Luiz Contente de Barros \& Fernando Antônio Teixeira Mendes

FERREIRA, C.M.C. As teorias de localização e organização especial da economia. In: HADDAD, Paulo Roberto (Org.). Economia regional: teorias e métodos de análise. Fortaleza: BNB. ETENE, 1989. (Estudos Econômicos e Sociais).

FILGUEIRAS, G.C. Crescimento agrícola no Estado do Pará e a ação de políticas públicas: avaliação pelo método shift-share. 2002. 156 f. Dissertação. (Mestrado em Economia). Universidade da Amazônia, Belém, 2002.

Economia florestal no Estado do Pará: uma abordagem locacional e intersetorial. 2007, 237 f. Tese (Doutorado em Ciências Agrárias). Universidade Federal Rural da Amazônia, Belém, 2007.

FUJITA, M.; KRUGMAN, P.R.; VENABLES, A.J. Economia espacial. São Paulo: Futura, 2002.

HADDAD, P.R.; FERREIRA, C.M.C.; BOISIER, S. ANDRADE, T.A. In: Paulo Roberto Haddad (Org.). Economia regional: teorias e métodos de análise. BNB. ETENE, 1989. 694 p.

HOMMA, A.K.O. Fontes de crescimento da agricultura paraense, 1970/80. Belém: EMBRAPA-CPATU, 1981. (Boletim de Pesquisa, 27).

INSTITUTO BRASILEIRO DE GEOGRAFIA E ESTATÍSTICA. Produção da extração vegetal e da silvicultura: Pará - 2004 e 2005. Disponível: http://www.ibge.gov.br. Acesso em: mar. 2006.

INSTITUTO DE PESQUISAS ESPACIAIS. Dados sobre desmatamentos na Amazônia: diversos anos. Disponível em: <www.inpe.gov.br>. Acesso em: mar. 2006.

LASTRES, H.M.M.; CASSIOLATO, J.E. (Coord.). Mobilizando conhecimento para desenvolver arranjos e sistemas produtivos e inovativos locais de micro e pequenas empresas no Brasil. Projeto apoiado pelo SEBRAE; dezembro de 2005. Disponível: htpp// 
redesist.ie.ufrj.br/glossário.php. Acesso em: mar. 2006.

MARSHALL, A. Princípios de Economia. Tradução revista: Rômulo de Almeida e Ottolmy Strauch. São Paulo: Abril Cultural. (Os economistas), 1982. v.II.

ROLIM, C. Reestruturação produtiva, mundialização e novas territorialidades: um novo programa para cursos de Economia Regional e Urbana. 1999. Disponível: www.economia.ufpr.br/publica/textos/1999/ txt0599\%20Cassio.rtd. Acesso em: abr. 2006.

SANTANA, A. C. Arranjos produtivos locais na Amazônia: metodologia para identificação e mapeamento. Belém: ADA, 2004. 108 p.

SANTANA, A. C. A competitividade sistêmica das empresas de madeira da Região Norte. Belém: M \& S Gráfica Editora, 2002.

Crescimento e estrutura da produção agrícola na Amazônia. Boletim FCAP, Belém, n. 17, p. 57-78, dez. 1988.

Elementos de economia, agronegócio e desenvolvimento local. Belém: GTZ; TUD; UFRA, 2005. 197 p.

SANTANA, A.C.; SANTANA, A.L.; FILGUEIRAS, G.C. Identificação e análise de arranjos produtivos locais na BR-163: 2002-2003 Amazônia: ciência e desenvolvimento. Belém; v. 1, n.1, p. 97 -119, jul./dez. 2005.

SANTOS, G.A.G; DINIZ, E.J.; BARBOSA, E.K. Arranjos produtivos locais e vantagens competitivas locais. Arranjos produtivos locais e desenvolvimento: versão preliminar. Fortaleza: BNDES, 2005. 
Abstract: At the present time, the State of Para is the third in the ranking of exports and concentrates $75 \%$ of the extracted wood from the nation's native forests. Of the extracted wood from the Legal Amazon, 64\% is directed to the national market while $36 \%$ is directed to export markets. The objective of this study was identify and to map, using the Normalized Index of Concentration (NIC), during the 1998 to 2004 period, the municipalities which are specialized in the forest, wood and furniture activities and that show significant potential to be transformed in local clusters. The results showed the existence of nine municipalities specialized, simultaneously, in the two activities, indicating the possibility of implementing public policies directed to influence the local sustainable development from those clusters with forest tradition. .

Keywords: Forest economics, concentration indexes, local development. 
REVISTA DE ECONOMIA E AGRONEGÓCIO, VOL.6, $N^{o} 1$ 